\title{
SOBRE EL ORIGEN Y DIFUSIÓN DEL NOMBRE "AMÉRICA LATINA" (O UNA VARIACIÓN HETERODOXA EN TORNO AL TEMA DE LA CONSTRUCCIÓN SOCIAL DE LA VERDAD)"
}

POR

\author{
MÓNICA QUIJADA
}

Centro de Estudios Históricos, CSIC

Existe una interpretación que afirma que la génesis y difusión del nombre de "América Latina" son un producto exclusivo del proyecto expansionista francés liderado por Napoleón III. Esta interpretación ha sido asumida colectivamente y convertida en "autoridad", a pesar de los problemas que presenta y de las inatendidas refutaciones que ha recibido. Este artículo se propone cuestionar dicha interpretación mediante una revisión de las nociones existentes sobre el tema, lo que implica examinar los problemas que presenta la versión canónica mencionada, recuperar información y elaboraciones previas que la ponen en duda, y proponer una interpretación alternativa que tenga en cuenta el contexto de origen, los ritmos de difusión y las connotaciones simbólicas del nombre que facilitaron su adopción mayoritaria.

“...truth lives on a 'credit system'. Our thoughts and beliefs pass, so long as nothing challenges them, just as bank-notes pass so long as nobody refuses them". ${ }^{1}$

* Este artículo se integra en el proyecto PB96-0868 (DGES) "Raza, nación y pensamiento científico en la construcción de las identidades americanas en el tránsito de siglo, 1870-1930". Su origen se encuentra en una conferencia titulada "Why Latin America? The dubious origins of an ambiguous concept", que la autora impartió en la Universidad de Cornell (USA) el 25 de abril de 1997, en una jornada sobre el tema "The Invention of Latin America".

1 W. JAMES, Pragmatism (1907), citado en Steven SHAPIN, A Social History of Truth. Civility and Science in Seventeenth-Century England, Chicago and London, The Chicago University Press, 1994, p. 6. 
"...truth is linked in a circular relation with systems of power which produce and sustain it, and to effects of power which it induces and which extend it". ${ }^{2}$

En un trabajo que se remonta a 1965, el prestigioso historiador norteamericano John Leddy Phelan - especialmente conocido por su monografía sobre el milenarismo franciscano en la Nueva Espa$\tilde{n}^{3}{ }^{3}$ - abordó con particular éxito de recepción el problema del tan difundido nombre de "América Latina".

Desarrollando un tipo de interpretación al que la intelectualidad de los años sesenta era particularmente sensible, Phelan afirmó que la nomenclatura en las Américas había funcionado a menudo como una proyección simbólica de las ambiciones y designios de las potencias europeas con respecto a los territorios descubiertos por Colón. Ejemplo de ello sería el término "Nuevo Mundo", que en los inicios de la colonización habría reflejado las aspiraciones franciscanas a la construcción de un nuevo espacio social y espiritual donde los indígenas - sencillos e inocentes - contribuirían a configurar un Cristianismo libre de los vicios del viejo mundo. De la misma manera el nombre de "América Latina" habría sido concebido, tres siglos más tarde, como un "programa de acción" destinado a integrar a las nuevas repúblicas americanas, recientemente desprendidas de la corona hispánica, en los planes y aspiraciones de una Francia en plena expansión imperial ${ }^{4}$.

2 M. Foucault,Power/Knowledge: Selected Interviews and other Writings 19721977 (1980), citado en SHAPIN [1] pp. 6-37

3 John L. PHELAN, El reino milenario de los franciscanos en el Nuevo Mundo, México, Instituto de Investigaciones históricas/Universidad Nacional de México, 1972 ( $1^{\circ}$ ed. en inglés: 1956). Del mismo autor, entre otros: The Hispanisation of the Philippines: Spanish aims and Filipino responses, 1565-1700, Madison, University of Wisconsin Press, 1959; The Kingdom of Quito in the Seventeenth Century: Bureaucratic Politics in the Spanish Empire, Madison, Milwaukee y Londres, University of Wisconsin Press, 1967.

4 John Leddy PhelAN, "El origen de la idea de Latinoamérica", en Ideas en torno de Latinoamérica, México, Universidad Nacional Autónoma de México/Unión de Universidades de América Latina, 1986, pp.441-455. La primera edición de esta conferencia en Idem, "Pan-latinism, French intervention in Mexico (1861-1867) and the genesis of the idea of Latin America", en Conciencia y autenticidad históricas. Escritos en homenaje a Edmundo O’Gorman, México, UNAM, 1968, pp. 279-298. 
La argumentación -que aquí se expone de forma muy suscinta- era como sigue: la denominación "América Latina" habría sido inventada y difundida en Francia en la década de 1860, con el objeto de justificar el proyecto expansionista de Napoleón III. En concreto, habría sido empleada por primera vez en 1861 en un artículo publicado por la Revue des Races latines, y sólo en fechas más tardías lo habrían comenzado a utilizar los propios hispanoamericanos. Según esta interpretación, la invención del término no puede entenderse más que en el contexto del movimiento Panlatinista - del que la publicación mencionada era acérrima defensora - y como parte de un programa político destinado a promover los intereses de Francia en América 5 .

Siguiendo esta interpretación, "América Latina" entraría en la lista de denominaciones destinadas a reflejar simbólicamente los designios de las potencias europeas con respecto a los países de la región. En este caso, la noción de "latino" aplicada a una porción del nuevo continente fue identificada con Francia. Y no con este país en tanto productor y difusor de formas culturales específicas, sino en su carácter de Gran Potencia. Para usar una categoría muy en boga hace treinta años, el adjetivo "latino" asociado a América fue vinculado al Imperialismo francés.

Tan grande fue el éxito de esta interpretación, que hoy no se pone en duda que sea ésta la única y "verdadera" génesis del nombre "América Latina". Dicho en otras palabras, esta versión se ha convertido en "autoridad". Es decir, en una afirmación (juicio, concepto, explicación o interpretación) que es aceptada colectivamente, de forma acrítica, a partir del "crédito y fe" que se han depositado en el autor o responsable del mismo'.

Lo cierto es que a pesar de esa consagración generalizada, la idea de que el nombre de "América Latina" es un producto exclusivo del expansionismo francés no viene avalada por una argumentación sin fisuras. Por el contrario, dicha argumentación presenta varios problemas de diferente envergadura, cuya resolución constituye en todos los casos un interesante desafío para la investigación. Más aún,

\footnotetext{
5 Idem.

6 Según el Diccionario de la Real Academia Española de la Lengua, "autoridad" es el "crédito y fe que, por su mérito y fama, se da a una persona o cosa en determinada materia" (acepción 6), y el "texto, expresión o conjunto de expresiones de un libro o escrito, que se citan o alegan en apoyo de lo que se dice" (acepción 8).
} 
algunas de las afirmaciones básicas que la sostienen han sido cuestionadas en unas pocas pero incisivas publicaciones que, sorprendentemente, nunca fueron tomadas en cuenta. Y esta desestimación ha sido tan acrítica, como acrítica fue la aceptación colectiva de la versión del profesor norteamericano.

Como ha dicho Steven Shapin, solemos aceptar como "verdad científica" lo que, en realidad, es el resultado de un juicio colectivo que "estabiliza" una afirmación y la convierte en "verdad", a partir del crédito que se otorga al emisor?. Esta "construcción social de la verdad" se basó en el siglo XVII en un sistema de "confianza social" $\mathrm{e}$, indudablemente, en un esquema de poder. En el siglo XX tendríamos que agregar, quizá, los resortes (redes académicas, medios de comunicación, etc.) que hacen a algunos grupos más visibles que a otros y que contribuyen al éxito, o no, de una teoría dada, a partir de factores que son ajenos a la "veracidad" intrínseca de la misma.

En todo caso, en las páginas que siguen me propongo someter a revisión las nociones existentes sobre el surgimiento y difusión del término "América Latina", lo que implica 1) llamar la atención hacia los problemas que presenta la versión canónica antes señalada; 2) recuperar información y elaboraciones que la ponen en duda y abren otras vías para la comprensión de ese proceso histórico; y 3) proponer una interpretación alternativa que tome en cuenta los distintos hilos argumentales que surjan de esa contrastación.

\section{DUDAS Y PROBLEMAS}

La interpretación que vincula estrechamente la génesis del nombre "América Latina" al expansionismo decimonónico francés está lejos de ser una creación ex-nihilo. Muy por el contrario, la afirmación inicial o punto de partida de la misma ha sido plenamente confirmada por investigaciones posteriores, y esto quizá ha contribuido a conferir "verosimilitud" al conjunto del edificio a pesar de las debilidades que a continuación examinaremos. En efecto, como bien ha señalado el profesor Phelan, fue precisamente un francés quien habló por vez primera de una porción de América que era "latina" en cuanto a cultura, y la contrastó con una América diferente, portadora

7 ShAPIN [1], pp. 5-6.

R. I., $1998, \mathrm{n}^{\circ} 214$ 
de otra herencia cultural que él denominó "sajona" o "anglosajona". Por añadidura este francés, de nombre Michel Chevalier -intelectual, político, economista y viajero- hizo esta afirmación en el contexto de un conjunto de intereses que con toda justicia pueden ser descritos como "tendencias expansivas" por parte de Francia.

El soporte de esa afirmación fue un libro que M. Chevalier publicó en 1836, tras recorrer los Estados Unidos, México y Cuba. Dicha obra, que contenía impresiones y comentarios inspirados al autor en el transcurso de su extenso viaje, presentaba la historia del mundo en términos de rivalidad entre civilizaciones, idea que hasta el día de hoy parece mantener su atractivo en ciertos ámbitos intelectuales ${ }^{8}$. En concreto, Chevalier se refería a la competencia entre dos "razas" o culturas antagónicas y hostiles, surgidas ambas del origen dual de nuestra civilización occidental: la "raza" latina o romana, y la "raza" germana (en la que Chevalier incluía a los llamados "anglosajones").

Esta distinción entre dos ramas supuestamente rivales de la civilización occidental no era una idea original de Chevalier ${ }^{9}$. Sin embargo, su elaboración personal del tema incluía algo que hasta entonces no solía tomarse en consideración: la idea de que ambas ramas - la latina y la germana- se habían "reproducido" en América. Como la Europa meridional, Sud América era "latina" y "católica"; la América del Norte, por el contrario, era "protestante" y "anglosajona". Francia era, según Chevalier, la "primera" entre las naciones latinas. Nada más lógico que fuera este país el destinado a conducir a sus "naciones hermanas" en la lucha por la supremacía que estaban librando con la "raza sajona". En total coherencia con estas ideas tempranas, dos décadas después de la aparición de su libro Chevalier se convirtiría en uno de los más fervorosos partidarios de la invasión a México por parte de las tropas de Napoleón III.

A la inversa - y no casualmente- las propuestas iniciales de Chevalier coincidían plenamente con la justificación ideológica del

\footnotetext{
8 El libro de Samuel P. Huntington, El choque de las civilizaciones y la reconfiguración del orden mundial (1a edición en español: Barcelona, Paidós, 1997) no deja de ser una versión posmoderna de este tipo de visiones.

9 Sobre este tema véase Lily LITVAK, Latinos y anglosajones: orígenes de una polémica, Barcelona, Puvill Editor, 1980; Reginald Horsman, Race and Manifest Destiny. The Origins of American Racial Anglo-saxonism, Cambridge (Mass.), Harvard University Press, 1981.
} 
programa expansivo del Emperador, que apelaba al proyecto de unidad de los "pueblos latinos" a partir de tres rasgos supuestamente compartidos: el origen racial, las creencias católicas y unos mismos rivales: los germanos y anglosajones del norte y los eslavos del este. La incorporación a este programa de los países "latinos" de América permitiría a la nación líder, Francia, asegurarse recursos imprescindibles para su desarrollo industrial y tecnológico, por un lado, y frenar la expansión de los competidores anglosajones, por el otro ${ }^{10}$. De ahí la importancia de la idea inicial de Chevalier de que al otro lado del Atlántico existían poblaciones que podían reclamar su pertenencia a ese concepto amplio de "raza latina".

Ahora bien, en esta referencia a una América que sería supustamente "latina" hay una cuestión sutil pero significativa, sobre la que es conveniente detenerse. Chevalier nunca habló de "América Latina" como un nombre colectivo. Se limitó a utilizar el adjetivo "latino" para calificar a los habitantes de una porción determinada de dicho continente. En otras palabras, este personaje habló de una América que era "latina", como hablaba de una América "protestante" o de una América "católica". De la misma manera, la gente de su época se refería a una Europa "latina", o "anglosajona". El profesor Phelan conocía bien esta distinción, y por ello sostuvo que el nombre colectivo "América Latina" había surgido con posterioridad a la publicación antes mencionada de Chevalier. En concreto, dató ese surgimiento en un artículo publicado por la Revue des Races latines en 1861, precisamente el año en que la invasión de México se encontraba en su última fase de preparación. Los invasores harían uso del término "América Latina" como una forma de integrar la ocupación de México en el proyecto Panlatino que aspiraba a presentar un frente unido y reforzado a las "razas" rivales - anglosajona y eslava - mediante la unión de todas las naciones "latinas". Sólo con posterioridad a esta fecha la nueva denominación sería utilizada por los propios hispanoamericanos.

Como se ha dicho antes, esta interpretación tuvo una difusión y un éxito notables y fue asumida globalmente como "la verdad" en cuanto al origen del nombre "América Latina". Y esto se produjo a pesar de que dicha versión presentaba algunos problemas que fueron pasados por alto. En primer lugar no tenía en cuenta ciertos datos,

10 Cfr. nota 4 supra.

R. I., $1998, \mathrm{n}^{\circ} 214$ 
lo que podría atribuirse a un simple desconocimiento de los mismos: aparentemente el autor y su público receptor ignoraban que muchos hispanoamericanos venían aplicando el concepto de "latino" a las poblaciones de esa porción de América desde los comienzos de la década de 1850 .

Sorprendentemente, el mismo año en que Phelan expuso su versión (1965) apareció en Montevideo un breve trabajo titulado $\mathrm{La}$ idea de Latinoamérica. Su autor, el profesor Arturo Ardao ${ }^{11}$, mostraba en él que los hispanoamericanos habían empleado el término "América Latina" en fechas anteriores a las señaladas por Phelan. Este trabajo temprano fue sólo el inicio de una investigación de largo aliento que culminó quince años más tarde con la edición en Caracas de un libro titulado Génesis de la idea y el nombre de América Latina $^{12}$. Pocos años después otro investigador, Miguel Rojas Mix, publicaba en Toulouse un nuevo artículo en la misma línea que los trabajos de $\mathrm{Ardao}^{13}$. Ambos prueban fehacientemente que años antes de 1861 —en concreto, a lo largo de la década de 1850 - el concepto de "América latina" ya estaba siendo utilizado por destacados personajes hispanoamericanos, como el dominicano Francisco $\mathrm{Mu}$ ñoz del Monte, los chilenos Santiago Arcos y Francisco Bilbao y, sobre todo, el colombiano José María Torres Caicedo. Por qué estas investigaciones permanecen hasta el día de hoy prácticamente desconocidas y no consiguieron modificar la aceptación colectiva de la versión canónica que venimos comentando, es un tema de especulación en el cual no entraremos aquí, auque forma parte indudablemente de los procesos de "construcción social de la verdad" a que antes nos hemos referido.

Pero no es éste el único problema que ofrece la interpretación de Phelan. Existe una segunda cuestión, que podríamos llamar ideológica. En efecto, la perspectiva "imperialista" que propone hace muy difícil explicar, no ya el origen, sino la adopción del término por los

11 Arturo ARDAO, "La idea de Latinoamérica", Semanario Marcha No. 1282 (Montevideo), 27 de noviembre de 1965.

12 Arturo ARDAO, Génesis de la idea y el nombre de América Latina, Caracas, Centro de Estudios latinoamericanos "Rómulo Gallegos"/Consejo Nacional de la Cultura, 1980 (273 págs.).

13 Miguel Rojas Mix, "Bilbao y el hallazgo de América latina: Unión continental, socialista y libertaria...", Cahiers du Monde Hispanique et Luso-Brasilien-Caravelle, No. 46 (Toulouse) 1986, pp. 35-47. 
hispanoamericanos. Es decir, su rápido y notable éxito entre los propios "designados" por él. De hecho, esta perspectiva no tiene en cuenta una cuestión tan significativa como el rechazo y la acerba crítica con que las élites políticas e intelectuales de Hispanoamérica recibieron la invasión de México por las tropas de Napoleón III. En otras palabras, la admiración que estas élites sentían por la cultura francesa no es suficiente para explicar, en primer lugar, que en los mismos años de la ocupación sus propios explícitos y fervorosos críticos -que no ocultaban los sentimientos de rechazo y humillación que les producían la acción francesa en México y los designios imperiales de Napoleón III- estuvieran utilizando el concepto de "América Latina" y proponiéndolo como una categoría colectiva legítima y conveniente. En segundo lugar, esta interpretación tampoco explica el extraordinario éxito que alcanzó la nueva denominación entre el público receptor de Hispanoamérica.

Pero hay una tercera cuestión, tan significativa como las anteriores, que la tesis "imperialista" deja sin descifrar: por qué la noción de "latino", que excluye a toda la población de origen no europeo - en especial los indígenas - fue utilizada, y más aún, propuesta como una denominación colectiva, por intelectuales como el chileno Francisco Bilbao, que se caracterizó por ser un decidido campeón de la integración racial y defensor de los derechos de las "razas" menos favorecidas. Otro personaje que utilizó tempranamente esa denominación fue el cubano José Martí, también conocido por su defensa de la integración étnica.

En otras palabras, la perspectiva asociada a los designios imperiales coloca a quienes estuvieron estrechamente comprometidos con la génesis y difusión del nombre "América Latina" en una posición de receptores pasivos y acríticos. La intención de este trabajo es, precisamente, devolver el papel protagónico a los principales actores de ese proceso, a partir de dos propuestas iniciales: 1) "América Latina" no es una denominación impuesta a los latinoamericanos en función de unos intereses que les eran ajenos, sino un nombre acuñado y adoptado conscientemente por ellos mismos y a partir de sus propias reivindicaciones. Dicho de otra manera: al promediar el siglo XIX era común utilizar el adjetivo "latino" para calificar tanto a una porción de Europa como de América. Pero la "Europa latina" nunca se convirtió en un nombre. Lo contrario ocurrió con "América Latina", y este concepto, en tanto denominación colectiva, no fue 
una invención francesa o europea sino hispanoamericana, como bien han demostrado las investigaciones de Arturo Ardao y Miguel Rojas $\mathrm{Mix}^{14}$. 2) Precisamente por ello, para comprender el surgimiento y difusión del nombre "América Latina" es necesario tener en cuenta sobre todo el contexto hispanoamericano de la época, más que el francés o el europeo. No estoy negando con esto que el entorno de Napoleón III empleara dicho nombre durante y después de la invasión de México como forma de legitimación de la misma. Pero la génesis, difusión y adopción colectiva del término corresponden a un horizonte más amplio que la mera utilización del mismo en el contexto del programa expansivo del Emperador. Lo que importa aquí no es tanto la relación de los franceses con el término que nos ocupa, como la de los propios latinoamericanos.

Para ahondar en estas cuestiones, creo necesario detenerse en el contexto ideológico en el que tomó forma y se difundió exitosamente el concepto de "América Latina". Esto implica examinar con cierto detenimiento tres cuestiones: 1) las circunstancias políticas e ideológicas que preocupaban a los latinoamericanos cuando se produjo el surgimiento y adopción del término; 2) las ideas y paradigmas globales en que se inscribe este proceso, y que operaban entonces no sólo en América, sino en el conjunto del mundo occidental del cual dicho continente forma parte; 3 ) finalmente, es importante procurar la identificación de aquellas connotaciones simbólicas del concepto "latino" que puedan haber facilitado su adopción mayoritaria por los propios hispanoamericanos, como una vía para explicar las razones de esa amplísima difusión.

\section{ORÍGENES, CONTEXTOS Y DIFUSIÓN}

Los hispanoamericanos comenzaron a utilizar el adjetivo "latino" asociado al nombre "América" en los inicios de la década de 1850, y generalmente en el marco de viajes a Francia realizados por algunos de ellos. El caso más antiguo que se ha encontrado se remonta a 1851. Durante la primera mitad de esa década gente como el domi-

\footnotetext{
14 Para desarrollar esta parte del argumento, me apoyaré particularmente en la exhaustiva y excelente investigación de Arturo ARDAo antes citada: Génesis de la idea y el nombre de América Latina (nota 12 supra).
} 
nicano Francisco Muñoz del Monte y el chileno Santiago Arcos hicieron esa asociación para describir los movimientos expansionistas de los Estados Unidos en el continente americano como una agresión de la "raza anglosajona" hacia la "raza latina".

Esta utilización no era en sí misma especialmente significativa, y sólo implicaba que los hispanoamericanos conocían y asumían las tendencias ideológicas más en boga en la Europa de la época. De hecho, al promediar el siglo XIX era tan normal hablar de las "razas" en general, de la división del género humano en "razas superiores" e "inferiores" e incluso de las rivalidades entre la "raza latina" y la "germana" o "anglosajona", como lo es hoy referirse a "culturas", a "naciones", o a las rivalidades entre Estados. Sin embargo, cuando los hispanoamericanos tomaron el adjetivo "latino" y lo aplicaron a sus propias poblaciones, se estaban refiriendo a un contexto que no coincidía plenamente con el que inspiraba a franceses, españoles e italianos. Para los europeos del sur, la supuesta existencia de una "lucha de razas" en la que las naciones latinas estaban siendo adelantadas por sus competidoras se asociaba en primer lugar a los avances técnicos, económicos y sobre todo geopolíticos de Gran Bretaña, a los que se añadían, en un plano inferior, los progresos de su "hija" americana, los Estados Unidos. En segundo lugar, a los europeos del sur y en particular a los franceses les preocupaba el "despertar" de las naciones eslavas, fundamentalmente la Rusia de los zares.

El contexto que motivaba los temores de los hispanoamericanos y en cuyo marco inscribían su propia percepción de la "lucha de razas" era mucho más restringido, geográficamente hablando: se refería fundamentalmente a la política de los Estados Unidos con respecto a los países que estaban al sur de sus fronteras. En los años cincuenta esa política tenía una faz muy concreta: los esfuerzos tempranos realizados por el gobierno de Washington para posibilitar la apertura, en la región centroamericana, de un canal que uniese los dos océanos. De ahí que la filiación "latina" fuese reivindicada por varios políticos e intelectuales hispanoamericanos en el contexto de la cólera e indignación que produjo en el continente la invasión de Nicaragua por parte del ciudadano norteamericano William Walker, considerado por todos un aventurero y un pirata. Walker intervino en Centroamérica entre 1855 y 1860, con el objeto de incorporar a los cinco países del Istmo como otras tantas estrellas a los Estados

R. I., 1998, n. $^{\circ} 214$ 
esclavistas sureños de la Unión, y en poco tiempo tomó control de la política nicaragüense y ocupó la primera magistratura del país. Pero los sentimientos de humillación que la acción de Walker provocó entre las élites hispanoamericanas no se debieron tanto a este personaje - al fin de cuentas, casi un delincuente común - como al hecho de que sus actividades recibieran el apoyo público y explícito del Presidente de los Estados Unidos, Franklin Pierce, quien le reconoció oficialmente como gobernante máximo de Nicaragua y envió un representante diplomático a Managua.

Por añadidura, el temor que despertaban las intenciones de Washington con respecto a Centroamérica y al Istmo de Panamá operaba sobre las heridas aún abiertas de la ocupación de Texas y la guerra subsiguiente, que le valió a México la pérdida de extensos territorios. La expansión de los norteamericanos sobre el país más septentrional de la América española había consternado a los americanos del sur; y muchos se preguntaban, al verles actuar en Centroamérica, si esa política expansionista no continuaría hasta el Cabo de Hornos.

Este conjunto de sentimientos negativos llevó a que muchos hispanoamericanos volvieran los ojos hacia el viejo sueño unionista del gran Libertador, Simón Bolívar. Sin duda, la razón principal que inspiraba la reaparición de aquellos ideales era la necesidad, sentida por muchos, de oponer al poderío creciente y a la política agresiva de los Estados Unidos una Hispanoamérica fortalecida por el esfuerzo común. Ahora bien, estas propuestas de mediados del siglo presentaban un matiz que había estado ausente de los llamamientos a la unidad en los tiempos de Bolívar. Lo que aparecía como nuevo e inédito en los cincuenta era, precisamente, la categoría "raza". En otras palabras, ni el Libertador ni ningún otro prohombre de la Independencia hubieran basado sus propuestas unitarias en argumentos tales como "el peligro de absorción de una raza por otra". Pero, como se ha dicho antes, la utilización de categorías raciales estaba muy extendida al promediar el siglo ${ }^{15}$.

15 Es interesante señalar que ya en 1837 (es decir, un año después de la publicación de Michel Chevalier a que nos hemos referido en el apartado anterior), Alexis de Tocqueville afirmaba en su obra Democracia en América, que iba a alcanzar una extraordinaria difusión: "Los españoles y los angloamericanos son, en realidad, las dos razas que se reparten las posesiones del Nuevo Mundo". A continuación, Tocqueville vaticinaba el poblamiento primero y la toma de posesión después, de extensos territorios mexicanos por parte de los 
Desde mi punto de vista, lo que influyó de manera decisiva en la emergencia y difusión exitosa del nombre "América Latina" fue, precisamente, la confluencia de lo que podríamos llamar la "racialización" de las categorías, por un lado, y la reaparición de las tendencias que abogaban por la unidad de los países de la América española como respuesta a las agresiones territoriales norteamericanas, por el otro. La primera de esas circunstancias - la racialización de las categorías - formaba parte de una tendencia general en Occidente. La segunda - la revitalización defensiva de una aspiración unionista preexistente, prestigiada por la imagen del que ya era venerado como el gran Libertador del Nuevo Mundo- era estrictamente americana. Esta confluencia es fundamental para comprender por qué, mientras que la idea de una Europa "latina" no implicó que se acuñase una denominación colectiva, en el caso americano, por el contrario, condujo a la invención del nombre genérico "América Latina".

Esta afirmación se entenderá mejor si nos detenemos brevemente en el proceso seguido por algunos notables ensayistas hispanoamericanos, comenzando por el colombiano José María Torres Caicedo quien fue con toda probabilidad — es decir, en la medida en que no se encuentren nuevos testimonios- el padre del invento. Torres Caicedo era un conocido abogado, periodista y ensayista, y ejerció una influencia considerable en los círculos sudamericanos de su tiempo. Fue, además, una de las personas más activas en favor de la unidad política de los países de la América española.

En el año de 1850, Torres Caicedo escribió acerca de la necesidad de estrechar los lazos entre la repúblicas sudamericanas para resistir los avances de los Estados Unidos en el área centroamericana. Lo que nos importa señalar con respecto a este escrito temprano, es que no se menciona en él la palabra "raza". Seis años más tarde, en 1856, este mismo personaje hizo un llamamiento a que se construyese una Confederación de las Naciones de la América Española, en el que hablaba del peligro que acechaba a la "raza española" en América de ser absorbida por la "raza sajona"16. Como puede obser-

norteamericanos de una manera que diez años más tarde se cumpliría casi literalmente. Aunque Tocqueville, a diferencia de Chevalier, no intentó hacer de esta afirmación una teoría, el párrafo citado es una manifestación temprana aplicada a América de la visión "racializada" de las rivalidades internacionales.

16 ARDAO [12], p. 173.

R. I., $1998, \mathrm{n}^{\circ} 214$ 
varse, al emplear esta terminología Torres Caicedo no hacía más que integrarse en una tendencia más amplia que hemos denominado como "racialización de las categorías", a la que pertenecía también un tipo de discurso muy popular en América del Norte que, por cierto, contribuía no poco a alimentar los temores de los vecinos del sur ${ }^{17}$. Pero nadie había mencionado todavía un ámbito geográfico llamado "América Latina".

Un poco más avanzado ese mismo año de 1856, Torres Caicedo hizo un segundo llamamiento a la unidad en un formato completamente distinto al anterior. Se trataba en este caso de un extenso poema titulado "Las dos Américas", en el que el escritor colombiano hablaba en tonos fervorosos de los peligros que entrañaba la América del Norte para los países que se hallaban al sur de sus fronteras, y urgía a sus compatriotas hispanoamericanos a unirse para enfrentar esa amenaza. En la novena parte del poema aparecían las siguientes líneas:

La raza de la América latina al frente tiene la sajona raza ${ }^{18}$.

Es muy probable que estos versos marquen el nacimiento del nombre colectivo "América Latina"19. En ese mismo año de 1856 el chileno Francisco Bilbao utilizó un adjetivo de nuevo cuño, refiriéndose a la existencia de una "raza latinoamericana ${ }^{20 "}$. Es decir, no ya "raza latina", sino "latinoamericana". En 1858 Torres Caicedo vol-

\footnotetext{
17 Ejemplo de ello es la siguiente frase del Presidente norteamericano Buchanan, datada en 1857: "Está en el destino de nuestra raza extenderse por toda la América del Norte, y esto se realizará dentro de poco tiempo si los acontecimientos siguen su curso natural. La emigración seguirá hacia el sur, y nadie podrá detenerla. Dentro de poco tiempo, la América Central contendrá una población angloamericana, que trabajará para bien de los indígenas". Citado en Héctor H. ORJuEla, Imagen de los Estados Unidos en la poesía de Hispanoamérica, México, Universidad Nacional Autónoma de México, 1980, p. 95.

18 El texto completo del poema puede encontrarse en ARDAO [12], pp. 175-185.

19 Para este tipo de "guerra de imágenes" en la literatura de ambas Américas véase la interesante monografía de Héctor H. ORJUELA [17]. Sorprendentemente, este autor no menciona el extenso poema de Torres Caicedo al que hemos hecho referencia. Otro análisis también basado en las relaciones literarias es el de José de Onís, Los Estados Unidos vistos por escritores hispanoamericanos, Madrid, Ediciones Cultura Hispánica, 1956.

20 ROJAS MIX [13], p. 36; ARDAO [12], p. 82. Este autor duda sobre si la paternidad del término "América Latina" debe atribuirse a Torres Caicedo o a Bilbao. En el caso del segundo, afirma, "el concepto se acuña en el marco de un pensamiento anticolonialista, antiimperialista y de un proyecto de sociedad socialista" (p. 38).
} 
vió a ocuparse del tema, escribiendo acerca de la Repúblicas "Latinoamericanas", y a partir de entonces utilizaría estos apelativos con asiduidad creciente. En 1861 publicó un panfleto titulado Bases para la formación de una Liga Latino Americana, y en 1865 un libro que llevaba por nombre: Unión Latino Americana.

Al finalizar los años cincuenta y comenzar la siguiente década, la nueva terminología estaba siendo empleada por numerosos hispanoamericanos. Es interesante destacar que su popularidad creció tan rápido que comenzó a ser aplicada a ciertos campos del conocimiento. Ejemplo de ello es que se empezó a hablar de una Literatura Latinoamericana y de escritores latinoamericanos. En 1862, el jurista argentino Carlos Calvo se refirió a "Los Estados de América Latina" en una importante recopilación de escritos jurídicos denominada Colección completa de los tratados, convenciones, capitulaciones, armisticios y otros actos diplomáticos de todos los Estados de América Latina, comprendidos entre el golfo de Méjico y el Cabo de Hornos, desde el año de 1493 hasta nuestros días ${ }^{21}$. En esa misma década de 1860 el nombre "América Latina" se difundió en el continente hasta el punto de ser utilizado en documentos oficiales de los gobiernos. Esto ocurría -insistimos- en los mismos años en que las tropas francesas habían ocupado México e instaurado un tipo de gobierno que repugnaba a la mayoría de las élites del continente, para quienes las formas republicanas tenían la fuerza de un mito de origen $^{22}$.

En resumen, fue en la década de 1850 que surgió el nombre de "América Latina", y su invención como tal correspondió estrictamente a los hispanoamericanos, en el marco de los temores que despertaba la política expansiva de los Estados Unidos. Su rápida difusión en la siguiente década entró en competencia con nombres más antiguos, como los de América Española, América del Sur o Gran Colombia. Algunos años más tarde, dos sucesos en el ámbito de la

21 Editado por la Librería de A. Durand, París.

22 Es interesante señalar que en el año 1853, el dominicano Francisco Muñoz del Monte escribió sobre la "latinidad" y sobre el peligro de absorción de la América de raza latina por el avance territorial de la raza anglosajona, pero afirmando que era y debía ser España la potencia europea tutelar de dicha latinidad. El artículo de Muñoz del Monte apareción en la Revista Española de Ambos Mundos, de Madrid. Señalemos también que este personaje es el primer publicista de Hispanoamérica que "desarrolla con amplitud doctrinaria la idea de la latinidad de ésta". Cfr. ARDAO [12], p. 69. 
geopolítica continental contribuirían a colocar al nombre de "América Latina" en una posición de ventaja con respecto a las denominaciones rivales.

En primer lugar, en el año de 1881 el Secretario de Estado James Gillespie Blaine propuso la celebración de una conferencia panamericanista, en el contexto de las rivalidades entre los Estados Unidos y las potencias europeas con respecto a las relaciones mantenidas con las restantes repúblicas americanas. La propuesta de Blaine, asociada a la revitalización de la doctrina Monroe en el marco del Manifest Destiny, no fue bienvenida en los círculos que abogaban por la creación de una Unión Latinoamericana. Ese mismo año, y en parte como respuesta a las iniciativas panamericanistas, tenía lugar en Buenos Aires la fundación de una publicación periódica - la $R e$ vista Latinoamericana - y de una institución - la Sociedad Unión Latinoamericana de las Repúblicas del Plata - que contribuirían considerablemente a la difusión generalizada del nombre "América Latina".

Más importante aún para la definitiva adopción del término fue el año mítico de 1898. La guerra entre España y los Estados Unidos en el contexto del movimiento cubano por su independencia colocó al concepto de "América Latina" en una posición privilegiada. Para comprender este último y definitivo impulso hay que tener en cuenta tres cuestiones de particular significación. En primer lugar, la mencionada guerra fue vista en Occidente como el último combate entre dos "razas" rivales, los "latinos" y los "anglosajones"23. Segundo: aunque los hispanoamericanos eran naturalmente partidarios de la independencia cubana, lo cierto es que la intervención de los Estados Unidos, unida a los malos modos, la prepotencia y el lenguaje ofensivo empleado tanto por el Partido de la Guerra como por el propio gobierno norteamericano, tuvieron como consecuencia que una mayoría de hispanoamericanos apoyase a España en esa lucha de "latinos" frente a "anglosajones" 24 .

23 Cfr. Mónica QuiJADA, "Latinos y anglosajones. El 98 en el fin de siglo sudamericano", Hispania, vol. LVII/2, núm. 196 (Madrid), mayo-agosto 1997, pp. 589-609.

24 Los sentimientos de humillación compartida que la prepotencia de Washington provocó en los hispanoamericanos, y el efecto que tuvo de volcar las simpatías de las poblaciones de lado español a pesar del rechazo que tradicionalmente despertara la política de Madrid hacia Cuba, fueron claramente percibidos en la época por los observadores de terceros países. A modo de ejemplo transcribimos el siguiente párrafo de una carta enviada 
Finalmente, debe recordarse que en este contexto de sentimientos "prolatinos" y "antisajones" extremos, se produjo el surgimiento o revitalización de importantes movimientos ideológicos continentales. Por un lado el Arielismo, es decir, la famosa dicotomía de Ariel y Calibán propuesta por el escritor uruguayo José Enrique Rodó, que asociaba a América Latina con el espiritualismo y a los Estados Unidos con el materialismo. Las ideas principales de Rodó no eran nuevas; pueden encontrarse embrionariamente, por ejemplo, en algunos trabajos de Francisco Bilbao ${ }^{25}$. Pero fue Rodó quien convirtió esa famosa dicotomía en una doctrina. Junto con el Arielismo y surgiendo del mismo contexto bélico del 98, interpretado como una "lucha de razas", aparece también el nuevo impulso dado a las tendencias unionistas, cargado esta vez de un acento nuevo que expresa como nadie el argentino Manuel Ugarte. En efecto, frente a la concepción bolivariana de una "anfictionía" o "confederación", Ugarte va a sostener por vez primera la existencia de una "Nación Latinoamericana", fundamentándola en un esencialismo cultural de raíz herderiana.

Desde 1898 en adelante, "América Latina" adelantaría en difusión y uso a todas las denominaciones que rivalizaban con ella.

\section{LAS RAZONES DE UN ÉXITO}

Habiendo revisado los contextos en que surgió el nombre que nos ocupa, las circunstancias de su origen y los ritmos de su difusión, queda aún por despejar una importante incógnita. En efecto, ninguno de los procesos que hemos seguido en las páginas anteriores es suficiente para explicar las preferencias mayoritarias de las poblaciones americanas por el nombre "América Latina" en detrimento

\footnotetext{
por el representante británico en Santiago de Chile a su gobierno: “... although the Spanish administration in Cuba and the means adopted for the suppression of the rebellion in the Island are generally disapproved (...), the high-handed vulgarity and bluster displayed by the War Party at Washington are loudly condemned, as is also the unnecessary offensive language of the ultimatum". Gosling to Salisbury, 21 April 1898, FO/132/55. QuiJADA [23], p. 593.

25 Francisco BILbAO: "El Congreso normal americano", en Idem, El Evangelio Americano, Caracas, Biblioteca Ayacucho, pp.273-289. RoJAS MIX [13], pp.44-45; QUIJADA [23], pp. 603-604.
}

R.I., 1998, n. $^{\circ} 214$ 
de otras denominaciones, ni las razones profundas que subyacen a su notable éxito. Tampoco son satisfactorias las interpretaciones que suelen ofrecerse cuando se plantea este tipo de interrogantes.

La más extendida de esas interpretaciones es la siguiente: “América Latina" tiene la ventaja de la utilidad, ya que abarca un ámbito cultural y geográfico más extenso que otras denominaciones, como sería el caso de Hispanoamérica, América del Sur o América Central. En otras palabras: dentro del adjetivo "latino" se incluyen países y regiones del nuevo continente que fueron colonizados por "europeos latinos" no españoles, como la América portuguesa o la América francesa. Desde esta perspectiva ofrece incluso posibilidades genéricas más amplias que el propio término "Iberoamérica", de cuño mucho más reciente.

Es ésta sin duda una explicación coherente, muy difundida e indiscutible desde una perspectiva actual. No obstante, para el historiador plantea un problema. Aparentemente, el nombre "América Latina" no fue utilizado en este sentido cultural amplio hasta 1875 , cuando habían transcurrido casi veinte años desde su surgimiento. Para entonces, como hemos dicho, ya se empleaba incluso en documentos oficiales. No hay evidencia histórica de que con anterioridad a dicho año se haya usado esa denominación para abarcar, por ejemplo, un vecino tan conspicuo como Brasil. Por el contrario, la evidencia señala que durante varios años "América Latina" operó como un sinónimo estricto de "América Española". El propio Torres Caicedo, al reeditar en los años ochenta sus viejos escritos de la década del cincuenta, cambió sistemáticamente los términos "América Española" o "Sudamérica" por el de "América Latina", pero no se sintió obligado a modificar el ámbito geográfico hispanoamericano designado inicialmente por dicha denominación.

De hecho, la primera propuesta de unidad latinoamericana que incorporó una discusión sistemática sobre la inclusión de Brasil fue la expuesta por Manuel Ugarte a comienzos del siglo XX, a partir de la idea ya mencionada de la "Nación Latinoamericana". Por lo tanto, desde una perspectiva histórica la amplitud geográfica y cultural del concepto "América Latina" no explica la rapidez y el éxito de su difusión inicial.

Existe una segunda interpretación a la que se ha recurrido con frecuencia: los hispanoamericanos habrían echado mano de la filiación "latina" para diferenciarse de su antigua metrópoli. En particu- 
lar, habrían buscado expresar por ese medio un rechazo a los tiempos originales del vínculo España-América, es decir, el período de la conquista y la colonización. Esta versión presenta también algunos problemas. En primer lugar, la persona a la que las evidencias históricas conocidas hasta ahora señalan como el más probable responsable del surgimiento del término, José María Torres Caicedo, no se cuenta precisamente entre los hispanoamericanos que rechazaban a la Madre Patria y al pasado colonial; y ya hemos visto que hubo incluso quien propusiera a España "como país líder de la latinidad"26. Pero hay una segunda evidencia, mucho más importante, que contradice la interpretación antes mencionada: si algo queda fuera de toda duda en este tema del origen y adopción del nombre "América Latina" por los hispanoamericanos, es el hecho de que dicha denominación forma parte de una dicotomía "racial"; y el segundo término de esa dicotomía no es el adjetivo "español" o "hispano", sino "anglosajón". No existe ni un solo caso en que "latino" fuera utilizado como una distinción dicotómica con respecto al adjetivo "hispano".

Por consiguiente, las interpretaciones usuales no contribuyen a explicar la facilidad y rapidez con que la idea de "América Latina" fue adoptada por las poblaciones del continente. Es necesario, pues, intentar nuevas respuestas. En mi opinión, la dicotomía racial a la que nos hemos referido podría ser un buen punto de partida para ensayar una primera explicación.

En páginas anteriores he dicho que, desde mi punto de vista, en el surgimiento y éxito del nombre "América Latina" fue decisiva la confluencia de la racialización de las categorías, por una parte, y la revitalización de las tendencias unionistas hispanoamericanas en el contexto del expansionismo norteamericano, por otra. Si las rivalidades con los Estados Unidos hubieran sido vistas exclusivamente en su dimensión geopolítica, su proyección no hubiera sobrepasado los límites continentales. Pero la racialización extrema de las categorías que fue característica del siglo XIX permitió a los hispanoamericanos asumir la filiación "latina", lo que implicaba conferir a sus problemas continentales -es decir, locales- una proyección "universal".

En otras palabras, mediante la adopción del concepto "latino" la contraposición entre una América de raigambre española y otra in-

26 Ver nota 22 supra.

R.I., $1998, \mathrm{n}^{\circ} 214$ 
glesa podía ser inscrita en la dicotomía más amplia y "universal" que enfrentaba a los "latinos" con los "anglosajones". El concepto de "universal" en este caso refiere a su sentido más usual en el XIX, que lo asimilaba a "occidental", ya que según el pensamiento decimonónico la civilización occidental había alcanzado las más altas cotas de evolución y por ello estaba destinada a extenderse por todo el orbe. De tal forma, mientras que la idea unionista de Bolívar era continental, la que sustentó la aparición del nombre América Latina también lo era, pero asumió el áurea de una proyección universal.

La asimilación de las rivalidades intracontinentales a la tendencia más amplia y "universal" que confrontaba a "latinos" y "anglosajones" tenía una doble ventaja. En primer lugar, vinculaba el destino de la "raza latinoamericana" a la "raza latina" ajena al continente. Ello implicaba atraerse la atención y la solidaridad de una parte de Europa hacia los problemas de aquellas lejanas latitudes. Pero además suponía para los hispanoamericanos un importante elemento de reafirmación, porque les permitía verse a sí mismos no como un puñado de débiles países frente a un vecino mucho más poderoso, sino como protagonistas de la grandiosa "lucha de razas" que dividía internamente a la manifestación más alta del progreso humano, la civilización occidental.

Existe una segunda explicación posible, que no es alternativa a la anterior sino complementaria de la misma; es también menos coyuntural y menos "consciente" que ella. Hasta ahora nos hemos referido al concepto "latino" en el contexto ideológico de los dos últimos tercios del siglo XIX. Es decir, cuando la Lingüística Comparada y las ideas antropológicas ya habían conferido al término la connotación "racialista" que fue característica de la época 27 . Pero no es ocioso preguntarse si "la latinidad" y "lo latino" tenían algún significado o connotación simbólica especial en la longue durée de la tradición hispanoamericana.

Voy a basar esta última propuesta en un reciente trabajo del profesor francés Serge Gruzinski que aborda, con brillantez y erudi-

27 Cfr. Mónica QuIJADA, "Los 'Incas Arios'. Historia, lengua y raza en la construcción nacional hispanoamericana del siglo XIX”, Histórica, vol.XX/2, diciembre de 1996 (Lima), pp. 243-270. 
ción, el problema del significado y usos de la "latinidad" en los tiempos en que México era la Nueva España ${ }^{28}$.

Según Gruzinski, la "Latinidad" se encuentra en el corazón del proyecto imperial y colonizador de la corona de Castilla, fundado en una unidad política y cultural simbolizada por el Imperio, por la lengua de Roma y por la religión asentada en Roma. Por añadidura, los europeos apelaron a los modelos de la Antigüedad Clásica para describir el Nuevo Mundo, asentar su historia por escrito y reorganizar las lenguas y los saberes indígenas a partir de esquemas renacentistas y enciclopédicos. Todo ello implicó proyectar la cultura novohispana en un sistema globalizador que aspiraba a la universalidad. De tal forma, la Latinidad era la clave para alcanzar la universalidad.

Pero no sólo los europeos apelaron a la Latinidad. En el siglo XVI, los nobles indígenas que enviaban cartas al Rey de España para solicitar el reconocimiento de sus privilegios heredados, no solían utilizar la lengua de Castilla sino el Latín. Y los artistas indígenas que decoraban los templos erigidos para la adoración del Dios cristiano solían introducir en sus pinturas imágenes que combinaban símbolos de la Antigüedad Clásica con otros extraídos de sus propias tradiciones prehispánicas.

Mediante la utilización del Latín los nobles indígenas se situaban, por un lado, en un marco de referencia común y universal que superaba los límites del Imperio español tanto en el espacio como en el tiempo, y, por otro, en un nivel equivalente al de las restantes noblezas del Imperio, desde el cual exigir la restitución de antiguos privilegios. De tal forma, los medios de la retórica latina eran utilizados por los nobles indígenas para oponer resistencia a la pérdida de derechos, o para recordar a los conquistadores que en el pasado España también había sido pagana. De manera equivalente, los artistas indios utilizaron la mitología clásica como una suerte de pantalla que les permitía filtrar su propia y antigua mitología; en tanto que algunos mestizos - como el Inca Garcilaso en el Perú o Diego Valadés en México - encontraban en la tradición latina el método y el armazón para defender y propagandizar el mundo prehispánico.

28 Serge Gruzinski: Usos políticamente incorrectos de la latinidad. Conferencia dictada en la Caixa de Barcelona, Madrid, marzo de 1997. Agradezo al Prof. Gruzinski que me haya permitido utilizar el original de su disertación.

R. I., $1998, \mathrm{n}^{\circ} 214$ 
En cierta manera - afirma Gruzinski- la Latinidad actuó como un gigantesco 'lecho de Procusto' retórico y conceptual ${ }^{29}$.

Por ende, la Latinidad no sólo era la llave que abría las puertas hacia la "universalidad", sino que operaba también como un instrumento de defensa e ilustración del mundo indígena. Lo que hizo posible esta combinación fue el hecho de que la Latinidad abría un espacio de consenso, al actuar como un común denominador que estructuraba y reorganizaba un universo básicamente heterogéneo. De tal forma, según el Prof. Gruzinski, el encuentro de la Latinidad con otras tradiciones culturales fuera de Europa abrió el camino a complejos procesos de mestizaje cultural, al ofrecer "una configuración... una serie de nichos dentro de los cuales grupos y culturas fracturadas por la conquista y la colonización lograron inventar, construir y asumir nuevas identidades" 30 .

En resumen, en la tradición hispanoamericana "Latinidad" ha significado tanto aspiración a la universalidad, como una vía hacia el sincretismo, hacia procesos de mestizaje e integración. En mi opinión, es ésta la experiencia colectiva y acumulativa, el background inconsciente que preparó la fácil recepción del concepto de "América Latina" en el siglo XIX. Dicho de otra manera, el éxito notable del término América Latina tuvo que ver con el hecho de que ofrecía a los hispanoamericanos un espejo en el que todos los fragmentos podían reunirse en un nivel de integración superior y universalmente válido.

Ninguna denominación anterior o posterior -América Española, Hispanoamérica, Gran Colombia, Iberoamérica- podía ofrecer tanto en un siglo que se caracterizó, precisamente, por aspirar a la universalidad del progreso indefinido, al tiempo que se esforzaba por integrar las poblaciones heterogéneas en un nivel superior y homogéneo - la "nación"- para convertirlas en legítimas depositarias de la soberanía del Estado*.

29 Idem, p. 6.

30 Idem, p. 18.

Estando el presente trabajo en pruebas de imprenta, llegó a mis manos el artículo de Paul Estrade "Del invento de "América Latina" en París por Latinoamericanos (1856-1889), París y el mundo ibérico e iberoamericano, París X - Nanterre, 1998, donde se defiende también el origen latinoamericano - y no francés - del nombre "América Latina". 
The origin and dissemination of the name "Latin America" has been explained as a product of the French expansionist programme under Napoleon III. This version has been colectively accepted, and has become a "canonical" interpretation despite the problems it poses and the criticism it has raised, which has never been taken into consideration. This article intends to revise this version by examining its problems and inaccuracies, by drawing on information and previous critical elaborations, and by proposing an alternative interpretation which takes into account the original contexts, the pace of dissemination and the symbolical projections of the name "Latin" that paved the way for its successful adoption.

R. I., 1998, $\mathrm{n}^{\circ} 214$ 